\title{
Cultural Functions in the Translation of Metaphor
}

\author{
Lulu Wang \\ Canvard College, Beijing Technology and Business University, Beijing, China
}

\begin{abstract}
Metaphor has been studied for over two thousand years. Modern science has broadened the field of metaphorical study. This thesis attempts to probe into the translation of metaphor from a cultural perspective by analyzing and identifying its cultural connotations so that we could possibly seek for appropriate translation strategies.
\end{abstract}

Index Terms - cultural function, metaphor, translation

\section{INTRODUCTION}

Translating is a complex and fascinating task. I. A. Richards (1953) once claimed that translating is probably the most complex type o event in the history of the cosmos. This is because, as a cross-cultural communication event, it involves not only two languages but also two cultures. Although on the surface it seems to be interlingual transformation, it is actually conveyance across cultures. This common understanding has already been reached in the translation circle, for people's attentions have been shifted from emphas is on linguistic transfer towards mo re emphasis on cultural transfer. Metaphor has been studied for over two thousand years. However, traditionally it was confined to rhetoric and regarded as a kind of linguistic decoration. Modern science has broadened the field of metaphorical study. Lakoff's study from the angle of cognition has opened up a new world for the study of metaphor. Under the in fluence of culture, the translation of metaphors becomes the most important particular problem (Newmark, 2001).

\section{LITERATURE REVIEW}

The theoretical study of metaphor, running a long course from ancient Greek age to the present, may be divided into the following three periods on the whole:

1) the period of rhetorical study of metaphor, from Aristotle to Richards, or from 300 BC to the 1930s, treating metaphor merely as a rhetorical phenomenon in most cases;

2) the period of semantic study of the metaphor, from the beginning of the $20^{\text {th }}$ century to the 1970 s making semantic study of metaphor from different angles like linguistics, logic and philosophy;

3) the period of interdisplinary study of metaphor, from the 1970s to this day, doing multilevel and multi-dimensional research into metaphor from angles of cognitive psychology, philosophy, pragmatics, semiotics and hermeneutics.

Seen from the above, the theoretical study of metaphor has been constantly developing and deepening, especially in the 20th century.

As early as the fourth century BC, the ancient Greek philosopher Plato was adept at applying metaphor; however he just regarded metaphor as "ostentatious ornament". His pupil Aristotle was first to study metaphor seriously. Aristotle devoted a lot of space to metaphor in his Poetics and his Rhetoric. He thought, "The greatest thing by far is to have a command of metaphor", and "Everyone uses metaphor in conversation". His defin ition of metaphor was a broad one-giving the thing a name that belongs to something else. As to the nature of metaphor, he pointed out that being god at creating metaphor was being good at making comparis on between seemingly unlike things to find out resemblance. His view influenced the following two thousand years and more.

In the 1930, the coming out of Richards' The Philosophy of Rhetoric ended the domination of Aristotle's theory of metaphor. Richards broke through the confinement of traditional rhetoric to lexical level by treating metaphor as a semantic phenomenon and studying it at sentence level, and first advanced the concepts of "tenor" and "vehicle" and the view of interaction. Richards' expositions proclaimed the beginning of semantic study of metaphor.

As Searle said, Aristotle's view of comparison and Richards' view of interaction were the two major schools of metaphor theory before the 1970s.

The French semiotician Paul Ricoeur, in his The Rule of Metaphor which was published in 1975, applied semiotic and semantic theory to push forward the study of metaphor from lexical level to sentence level and to discourse level.

The philosopher John R. Searle, in his monography Expression and Meaning, studied metaphor from the angle of speech act theory. He thought metaphor was not merely a lexical or syntactic phenomenon, but also a discourse phenomenon, and the metaphorical meaning should be sought in broad linguistic environment.

Experts in prag matics believed metaphor, seen from its nature, partly belonged to pragmatics.

In the 1980 s, systematic functional linguistics joined the study of metaphor. M. A. K. Halliday, in his An Introduction to Functional Grammar, proposed the new concept of grammatical metaphor, which widened the field of metaphor.

The most outstanding characteristic of the modern study of metaphor is breaking through the restriction of rheto ric 
and making interdisciplinary research on metaphor, it is generally acknowledged that metaphor is not merely a rhetorical device, what is more important, it is a universal mode of thought and cognitive means. In 1980, G Lakoff and M. Johnson, in their joint work Metaphor We Live By, raised the significance of metaphor to a new height. They advanced a new opinion-metaphorical concept system, according to which metaphorical concepts of human were systematic, thereby people could understand an experience in terms of another. In the late 1980s, E. F. Kittay's Metaphor: Its Cognitive Force and Linguistic Structure pointed out that a lot of human action were constructed on the basis of metaphorical concepts, which meant metaphor had cognitive significance - in fact, it was metaphor that provided possibility for cognitive activities to transform into language; and not only in language, but also in dance, painting, music, movie and other artistic forms existed metaphor. Then in the nineties, B. Indurlhya published his Metaphor and Cognition, with the subtitle An Interactionist Approach, in which he supplemented and developed the Interaction Theory.

In recent years, more and more western linguists are fitting metaphor into study of thought and cognition, and numerous monographs on metaphor and thought or on metaphor and cognition have come out one after another. Metaphor now has been the matter of common interest not merely to rhetoricians but also to psychologis ts, philosophers, semioticians, etc.

The enthusiasm of studying metaphor reached the climax in the late 1970s, particularly in the United States. No wonder M. Johnson and other people called it in jest a metaphormania.

In the late $20^{\text {th }}$ century, this metaphormania spread to Chinese linguistic field, which were lagging far behind the western academic circle in the interdisciplinary study of metaphor. Many Chinese scholars have paid close attention to metaphor and articles on metaphor have appeared in publications in succession.

Shu Dingfang, a young scholar, has distinguished himself by his papers on metaphor, which respectively explore the nature and semantic features of metaphor, analyze the cognitive, psychological and linguistic causes of the product of metaphor, and introduce comprehensively the objective, methods and tasks of modern metaphorical research. Other researchers such as Zhao Yanfang, $\mathrm{Hu}$ Zhuanglin and Lin Shuwu, etc, also make their own contribution to modern metaphorical study in China. But there is still a long way for Chinese scholars to catch up with their western companions in the study of metaphor.

\section{PURPOSE AND METHODS}

This thesis discusses metaphor, a commonly used rhetorical device in both English and Chinese, and its translation by exploring the definition, classification, intercultural comparison and translation methods.

The study of metaphor has revealed that metaphor is not merely a linguistic phenomenon, but basically a cognitive phenomenon, a thinking mode; its production is thought to be the result of the limitation s of human thinking ability at primeval stage and later the result of people's active use for better communicative effect or for the sake of cognition. While language is the carrier of culture, metaphor reflects culture.

According to the purpose of translation, translators may fle xibly apply the basic approaches, considering the specific context and paying attention to the pitfalls in translation.

The research methods involved in writing this thesis are mainly: analysis, classification, exemplification, comparison, contrast, etc.

\section{ON METAPHOR}

\section{A. Definition of Metaphor}

Metaphor was defined earliest by Aristotle as "Metaphor is the application to one thing of a name to belonging to another thing." Metaphor, or the means by which one thing is described in terms of something else, has been described as a central tool of our cognitive apparatus. It is central to our understanding of how language, thought and discourse are structured.

\section{B. Classification of Metaphor}

Lakoff divided metaphors into three types: orientational metaphors(方位隐喻), ontological metaphors (实体隐喻) and structural metaphor(结构隐喻).

Orientational metaphors were that concrete orientation concepts such as up-down, in-out, front-back, on-off, deep-shallow and central-peripheral, were metaphorically based to express abstract concepts as feeling, mood, state of health, information quantity, social status and values.

e.g. Health and life are up. Sickness and death are down.

$\begin{array}{ll}\text { (1) He's in top shape. } & \text { (2) He feels ill. }\end{array}$

(3) 小姑娘的身体一天天好起来。(4) 他终于病倒了。

Orientaion concepts are widely applied to objects with orientation; this is the main character of orientational metaphors.

e.g. (1) Do you follow my point. (2) 法律面前人人平等。

Ontological metaphors were that to understand and experience concepts abstract, ambiguous and not easy to explain 
through concrete, visible and obvious substance.

e.g. The mind is a machine

1) My mind just isn't operating today.

2) 开动脑筋, 丢掉包袱, 轻装上阵。

In container metaphors which were part of ontological metaphors, all things could be considered containers, having edge, inside and outside.

e.g. States are containers
(1) He is in love.
(2) 他陷入沉思。

Structural metaphors are cases where one concept is metaphorically structured in terms of another.

e.g. Time is money

(1) I spend much time in reading. 花时间

(2) You're wasting my precious time. 浪费宝贵的时间

Structural metaphors have a strong cultural and emerge naturally in structures. Not only are they grounded in our physical and cultural experience; they also influence our experience and our actions.

\section{Functions of Metaphor}

Metaphor plays a great role in the field of rhetoric, language and cognition.

In the field of rhetoric, the apply of metaphor makes the expression more concise, vivid, enlightening, euphemistic and so on.

Linguistic metaphor is the reflection of conceptual metaphor in language. That is to say, we metaphorize one category into another at first, then there is the phenomenon of metaphorizing one word into another in language. For instance, "high" originally represents a spatial concept opposite to "low" or protruding over a level; when it is metaphorized into speed domain, we have the concept "high speed", if it metaphorized into scientific and technological domain, we have the concept "high technology".

When people cognate and describe things formerly unknown, they often depend upon concepts and expressions know to increase their knowledge and learning about things unfamiliar, and metaphor is the core of the process of giving the rein to imagination and association and linking unusually two things that seem to have no relation with each other, from simp le to complicate, from abstract to concrete, from familiar to strange and from one thing to another.

\section{LANGUAGE AND CULTURE}

What is language? What is culture? What is the relationship between culture and language? These fundamental questions are the ones to which a translator must give a priority before undertaking any translation task.

Today, it is generally accepted that language, as "a system of sounds, words, patterns, etc. used by humans to communicate thoughts and feelings" (Oxford Advanced Learner's English-Chinese Dictionary, 1997:878), or as “a semiotic system of expressing thought", is a crystallization of the total experience of a people's life and work. If language is taken into account in the broad background of human society, it is found that it is a product of culture and also a carrier of culture, for language reflects and records a nation's history, natural geographic conditions, economy, social system, religion, and folk customs and so on. It is no exaggeration to say that languages are integrated with cultures.

Compared with language, culture has a much broader meaning. It reflects the total pattern of beliefs, customs, institutions, objects, and techniques that characterize the life of a human community. And it is an integrated system of learned behavior patterns which are characteristic of the members of a society and which are not the result of biological inheritance. We can understand culture from the following as pects: First, culture is a social inheritance that was created through long-time hard work. Second, culture consists of not only non-material things such as beliefs, value concepts, custom knowledge, as well as material things. Third, culture is the guide of people's action and provides methods for us to solve the problems. Fourth, culture is not innate, it is learned. Lastly, different cultures can be distinguished by their core value concepts.

Language and culture are twin sisters. Language is a part of culture and plays a very important role in it. Some social scientists consider it as the keystone of culture. Without language, they maintain, culture would not be possible. On the other hand, language was influenced and shaped by culture; it reflects culture. In the broadest sense, language is the symbolic representation of a people, and it comprises their historical and cultural backg rounds as well as their approach to life and their ways of living and thinking. (Deng Yanchang, 1991) Language and culture are, of course, inextricably linked, so that learning language means learning culture and vice versa. Every society has its own culture. The Chinese culture, which has been influenced by Confucianism, Taoism and Buddhism for nearly three thousand years, is obviously different from the European culture, which consists of Greek myth and Christianity. For example, in Chinese, “孔雀” is a symbol of auspiciousness, while in English "peacock” is a derogatory term which means "proud", "flaunt”, “be puffed up” and so on. The phase “as proud as a peacock” means “像孔雀那样骄傲。” So it is hard to use language correctly without understanding its relevant culture. 


\section{INTERCULT URAL COMPARISON OF METAPHORS}

\section{A. The Generality of Metaphorical Concepts in Chinese and English}

1. Metaphorical concepts related to human body

Metaphorical concepts related to human body contain metaphors taking parts of human body as vehicles, those taking human body as referring planes those treating human body as containers and those of human feelings expressed by physiological reaction of human body to outside stimuli. In both Chinese and English, there are lots of such expressions as, a leg of table chair's back, which embody metaphorical concepts. The words like "leg" "back" indicate parts of human or animal body, when used to metaphorize other objects, they form vivid expressions easy to understand and accept. These names are established in language and these metaphorical concepts naturally become part of cultural generality. As human have the same senses and interlinked emotional reaction is basically the same among nations.

2. Metaphorical concepts related to nature

All human live on the same earth and the environment is generally alike; therefore, when applying objects in nature to metaphorize abstract concepts or those difficult to describe directly, different nations may adopt the same vehicles.

e.g. In both Chinese and English, flowers are used to indicate beauties: 这围女真是一朵花。/Oh, my love is a red, red rose.

\section{B. The Differences of Metaphorical Concepts}

The Chinese and the British and American peoples, thanks to the influence of various factors such as living regions, climates, ecological environments, history, religion and color of skin, have different cultures, which directly result in the dissimilarities of people's thinking mode and value orientation, and thus become the major cause for the differences of metaphorical concepts.

1. Influence of re lig ion and mythology

In the west, as a result of the wide spread of Christianity, people universally have the sense of salvation and original sin, and they believe God is the only deity; while in china, Buddhism. Taois $\mathrm{m}$, and Confusianism coexist over a long period of time and there are hundreds of divinities, showing the harmonious and all-embracing nature if Chinese culture which influences the production of metaphorical concepts.

归西 V. Jupiter's arrow

2. Influence of aesthetic standards and customs

The Chinese people and the British and American peoples belong to different races and have different cultures, thus the aesthetic standards and customs are dissimilar. The Chinese belong to the yellow race and consider black hair, black eyes and fair complexion to be beautiful; while the most of the British and Americans are white people who consider golden hair and blue eyes to be beautiful.

3. Influence of literature on metaphorical concepts

Classics are an important source of metaphors in various national languages. Metaphors from classics appear repeatedly in language and some gradually merge into people's thought which become concepts and lose the original meanings.

e.g. 刘姥姥进大观园

Romeo and Juliet are the symbol of pure love, and their names may ind icate respectively young men and women in love.

4. Influence of region and history

Traditionally, agriculture had been dominating in china since the ancient time, feudalism existed over two thousand years. While in tradition the chief living means of the British was fishing and hunting, England was the first industrialized country, it was powerful at sea and once possessed broad colony,. The marked regional and historical differences between the two nations have great influence on the thought, language and national character, which is expressed remarkably in the figures of speech and metaphorical concepts.

\section{TRANSLATION OF METAPHOR}

Scholars agree that metaphor has been sadly neglected in translation theory. This chapter is a brief discussion of metaphor translation in the light of oits possible translation procedures and translation methods.

Generally speaking, the criteria of translation are "faithfulness" "smoothness" and "elegance". In order to achieve these three principles, the following methods should be applied to translate metaphors.

\section{A. Literal Translation Approach}

Literal translation is generally regarded as the most important translation method in China. Professor Liu Chongde defines literal translation as follows: "In the process of translation, literal translation takes sentences as basic units and at the same time takes the whole passage into consideration; a translator who attaches great importance to literal translation does his or her best to reproduce the ideas and writing style of the orig inal work, retain ing as many rhetorical devices and sentence structures as possible."

Literal translation is thought by some scholars to be the most essential and the most commonly used method for 
translating metaphors. As long as the original meaning is not impaired, it is essential to give priority to literal translation, for it is able to maintain the basic structure of the original sentence and also the reproduce its artistic conception, image and intended meaning.

For example:

Breakfast without orange juice is a day without sunshine. (橙汁广告)

没有橙汁的早晨是没有阳光的日子。

以眼还眼，以牙还牙

An eye for an eye, a tooth for a tooth

Newmark said: It is necessary to reproduce the same image in the TL provided the image has comparable frequency and currency in the appropriate register. Obviously, this procedure is identical to literal translation.

\section{B. Vehicle-converted Translation Approach}

Every nation has its own distinctive ways of expression. As a result, metaphors formed in a particular nation are inevitably marked with the national color. To be more specific, distinct national characteristics can usually be detected from vehicles in metaphors. Therefore, when we meet those metaphors that can hardly be translated literally, it is necessary to convert the vehicles, that is, to resort to conversion translation approach to convert the images.

你这是孤注一掷。You are putting all your eggs in one basket.

To me, it's only a piece of cake. 对我而言, 这只是小菜一碟。

The conversion translation approach is employed to convert images and vehicles in order to translate the same intended meaning and to render the version faithful and easily understandable. This translation method respects the national individuality, national cultural differences and language individuality, and takes the acceptability of the translated versions into consideration.

\section{Free Translation Approach}

Free translation is supplementary to literal translation. Free translation is employed for the purpose of expressing the original meaning instead of reproducing the original sentence structure and rhetorical device. Only when literal translation is not suitable to use in a certain case, can the translator resort to free translation.

Free translation of metaphors means giving up the orig inal image or vehicle and making effort to find an appropriate way to express the intended meaning of the original metaphor.

e.g. Don’t cross the bridge till you get to it. 不要自寻烦恼。不要过早担忧。

\section{Translation with Addition}

While translating metaphors, some times we need to add some words to the translated version in accordance with the context in order to render the intended meaning clear-cut and complete, or to make the version conform to the id io matic usage of the TL.

A. Translation of metaphor by simile, retaining the image e.g. Speaking without thinking is shooting without aiming. 说话不经考虑, 犹如射箭不用瞄准。

B. Translation of metaphor into simile plus sense. (or occasionally a metaphor plus sense) e.g. Sorrow for a husband is a pain in the elbow 丈夫的悼亡, 就象肘部的一阵剧痛, 剧烈却短暂。

\section{E. Literal Translation plus Free Translation}

Some English metaphors are suitable to be translated both literally and freely. e.g. Today a man, tomorrow a mouse.

Literal translation: 今天是一个人, 明天是一头鼠。

Free translation: 今天得志, 明天落魄。

To provided the above metaphor with both literal and free translation helps the learners to grasp the hidden meaning through the literal meaning and then to master the essence.

Among the five method, literal translation is the most commonly used one; conversion translation is suitable for translating the metaphors that can not be translated literally but the vehicles or images of which can be converted in the TL; free translation is employed only when neither literal translation nor conversion translation is applicable; translation with addition is a supplementary method; whether to provide two versions of both literal and free translation depends on the particular situation.

\section{CONCLUSION}

As metaphor becomes a frontier subject correlated with various disciplines, people's understanding on metaphor is getting profound. Metaphor is widely used in English and Chinese. By intercultural comparison, we can see there are general characters and differences in Chinese and English metaphors. 
This thesis is an initial exploration of the definition, classification, function and translation of metaphors. It aims at helping Eng lish learners in china appreciate, apply and translate metaphor better.

\section{REFERENCES}

[1] Deignan, A. (2001). Metaphor. Beijing: The Commercial Press.

[2] Deng Yanchang, Liu Runqing. (2001). Language and Culture. Beijing: Foreign Lan guage Teaching and Research Press.

[3] Lakoff, G. \& Johnson, M. (1980). Metaphors We Live By. Chicago: The University of Chicago Press.

[4] Newmark, P. (1981). Approaches to translation. Oxford: Pergamon Institute of English.

[5] Newmark, P. (1988). A Textbook of Translation. Prentice Hall International (UK) Ltd.

[6] Nida, E. A. (2001). Lan guage, Culture, and Translating. Shanghai Foreign Lan guage Education Press.

[7] Richards, I. A. (1953). Toward a Theory of Translating. In Arthur F. Wright (Ed.), Studies in Chinese Thought (vol. 55). Chicago: Chicago University Press, 75.

[8] Shu Dingfang. (2000). Studies in Metaphor. Shan ghai: Shanghai Foreign Lan guage Education Press.

[9] Zhang Peiji, Yu Yungen. (1980). A Course in English-Chinese Translation. Shanghai: Shanghai Foreign Language Education Press.

Lulu Wang was born in Beipiao, Liaoning, China in 1980. She received her M.A degree in English Lan guage and Literature from China University of Petroleum in 2006.

She is currently a lecturer in Canvard College, Beijing Technology and Business University, Beijing, China. Her research interests include translation theory \& practice, English teaching and linguistics. 